\title{
Influence Affecting the Lifetime of Belt Conveyor's Drive Drums
}

\author{
Jiři FRIES, Tomáš HAPLA
}

\begin{abstract}
Belt slippage on drive drums of belt conveyors is generally considered as an undesirable phenomenon, which has a huge influence on wear of the drive drum lining or its destruction, reduces the operability of the entire device and should be then completely excluded from belt conveyor operation. Belt slips in the start-up phase can be long- or short-lasting with slight differences in speeds of the belt and drive drum and therefore cannot be registered. So it in necessary to seek options to avoid slips in a controlled start-up of belt conveyor. The paper suggests the effects of conveyor input parameters on the occurrence of those negative slips.
\end{abstract}

Keywords: belt conveyor; drive drum; measuring; lifetime; simulation; slippage; wear

\section{INTRODUCTION}

Besides the drum design especially the tensioning device and its reliability or effectiveness play a huge role in the drum lifetime. This may, depending on infilling the belt conveyor with a transported material, significantly affect the lifetime not only of drums, but also of other conveyor parts, such as motor drives, etc. The lack of tensioning force and effectiveness of the tensioning device causes slips of conveyor belts on driving drums, when due to "recatching" the belt by the drum shell at the point, where the belt is running on the drum, an immediate increase in tensile force in the belt occurs at this point to $4 \div 7$ times its initial value.

This force and vibrations are not transmitted along the conveyor, at they are quickly damped. However, they significantly affect the lifetime of drums (especially then the shaft lifetime) and also speed gears of gearboxes and hence also conveyor parts. However, they represent the greatest danger to mechanical belt joints located just near the point, where the belt is running on the drum.

\section{START-UP SIMULATION}

To regulate the tensioning force of the belt is important especially for long conveyors. When starting up the conveyor it is advisable or necessary to increase the tensioning force in a relatively large range, and then in steady operation to decrease it. Adjustable take-up units contribute to increasing lifetime of the conveyor belt. Commonly the tensioning devices with a screw and a weight are used and in cases of long distance transport or lack of space (underground mines) the tensioning devices (so-called carriages) as in Fig. 1 are used.

The simulation of that mentioned problem was carried out for a $1800 \mathrm{~mm}$ wide polyamide belt conveyor, with $2 \times 630 \mathrm{~kW}$ horizontally laid asynchronous motors with clutch and SEV gearbox located on the frame, maximum length of $800 \mathrm{~m}[1,2,4]$.

The maximum transmission capability of the drive drum is given by the relation:

$$
F_{\text {omax }}=T_{2} \cdot(\tau-1)
$$

Where:

$$
\tau=\mathrm{e}^{\mu \cdot \alpha}
$$

The friction coefficient considered in dependence on the slip speed:

$\mu=a+b \cdot \mathrm{e}^{-c \cdot v_{s}}$

After substituting into the relation above we obtain:

$$
\tau=A \cdot B^{\mathrm{e}^{-c \cdot v_{S}}}
$$

where $A=\mathrm{e}^{a \cdot \alpha} ; B=\mathrm{e}^{b \cdot \alpha}$. The curve of the $\tau$ value depending on the belt slip speed is shown in Fig. 2.

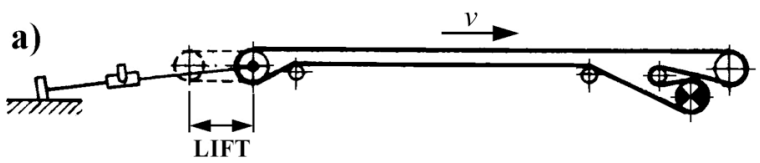

b)

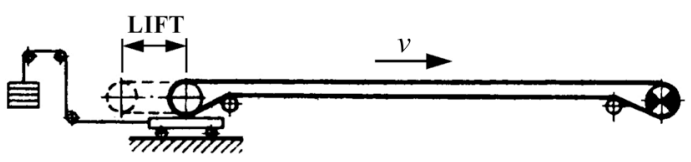

c)

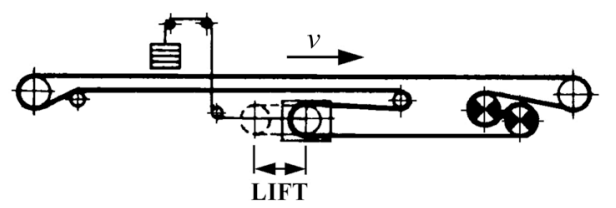

d)

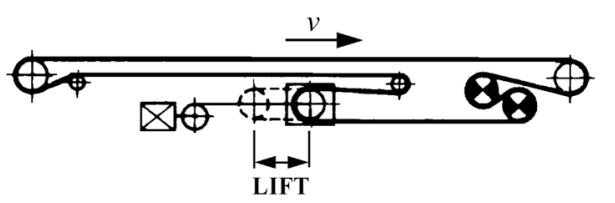

Figure 1 Basic schemes of a take up-unit

a) tensioning with a screw, b) tensioning with a weight on the return end conveyor, c) tensioning with a weight on the drive unit, d) automatic tensioning (using a winch, pneumatic linear motors, etc.)

Further conveyor parameters $[1,2]$ : rated speed $v_{\mathrm{j}}=$ $5.18 \mathrm{~m} / \mathrm{s}$; density of loose material $q=1.7 \mathrm{t} / \mathrm{m}^{3}$; amount of transported volume $V_{\mathrm{d}}=7500 \mathrm{~m}^{3} / \mathrm{h}$; friction coefficient $\mu=0.3$; angle of drum wrap $\alpha=180^{\circ}$; number of rollers in the upper branch $n_{\mathrm{h}}=3$; number of rollers in the lower branch $n_{\mathrm{d}}=2$; number of drives $p_{\mathrm{M}}=2$; driving drum (see Fig. 4) diameter $\mathrm{D}=1.4 \mathrm{~m}$; gear of gearbox $\mathrm{i}=14$; start- 
up time $t_{\mathrm{R}}=38 \mathrm{~s}$; tensile modulus of belt elasticity $E=$ $6.25 \times 10^{6} \mathrm{~N} / \mathrm{m}$; coefficient of belt element elasticity $c_{1}=$ $2.81 \times 10^{4} \mathrm{~N} / \mathrm{m}$; number of start-up steps $n_{\mathrm{sp}}=9$ (commonly used) $n_{\mathrm{sp}}=6$ (reduced - determining the effect of the number of start-up steps); motor speed $n_{\mathrm{s}}=$ $990 \mathrm{~min}^{-1}$.

A slip on the drive drum of the belt conveyor occurs during operation, particularly in the start-up phase of the belt conveyor. Fig. 3 shows curves of the approaching
$\left(T_{1}\right)$ and receding force $\left(T_{2}\right)$ on the drive drum of the mentioned conveyor. Fig. 5 then shows the behavior of the transmission capability reserve of the drive drum $F_{\text {rp. }}$. The conveyor is 800 meters long as mentioned above, horizontally laid, i.e. with zero camber while fully loaded. The belt pre-tensioning $\left(T_{\mathrm{p}}\right)$ was gradually reduced from $320 \mathrm{kN}$ to $240 \mathrm{kN}$. A slip begins when the value is negative $\left(F_{\text {rp }}<0\right)$ and lasts almost all the time during which this magnitude takes negative values.
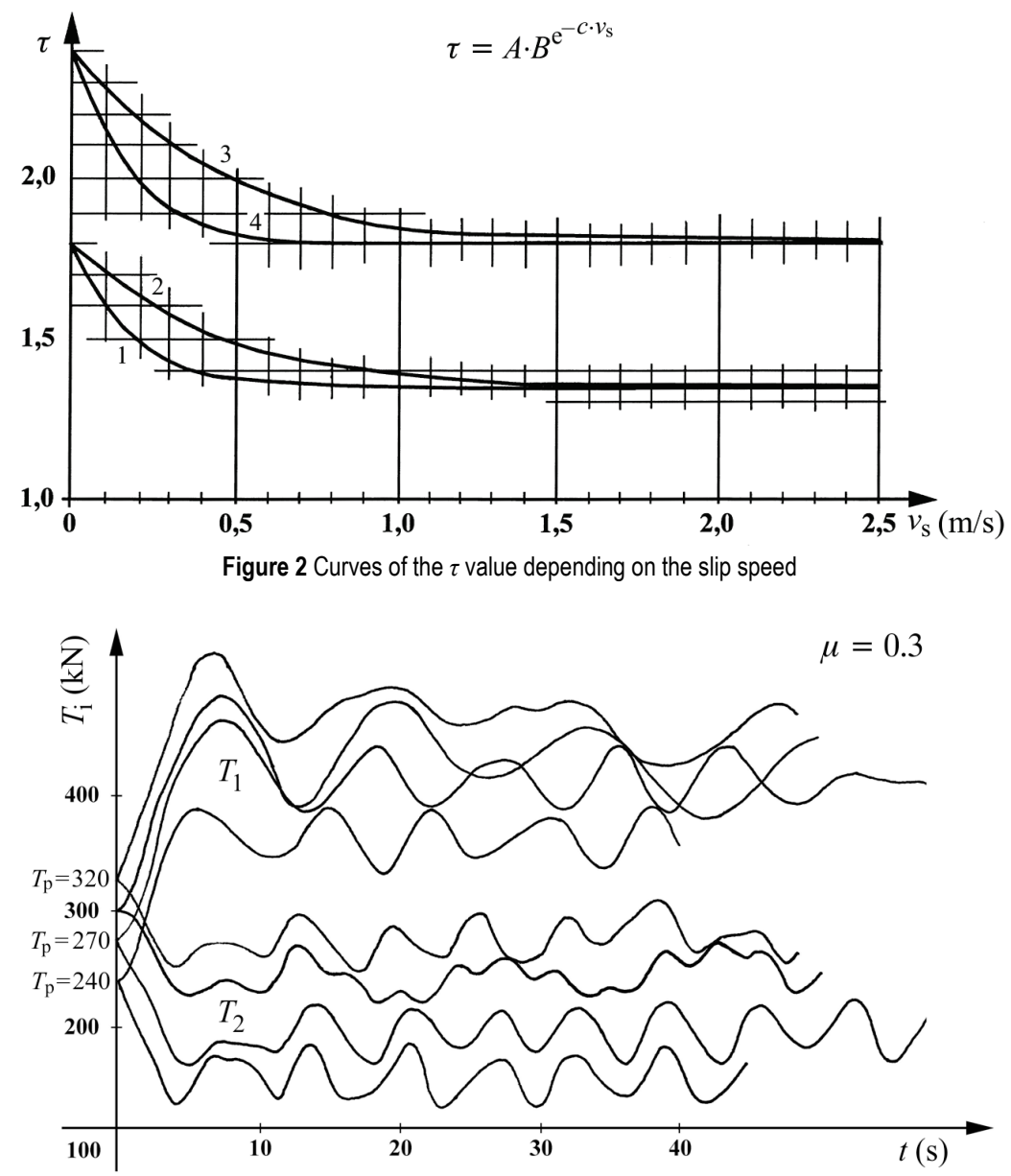

Figure 3 Behavior of the approaching and receding forces of the drive drum - fully loaded

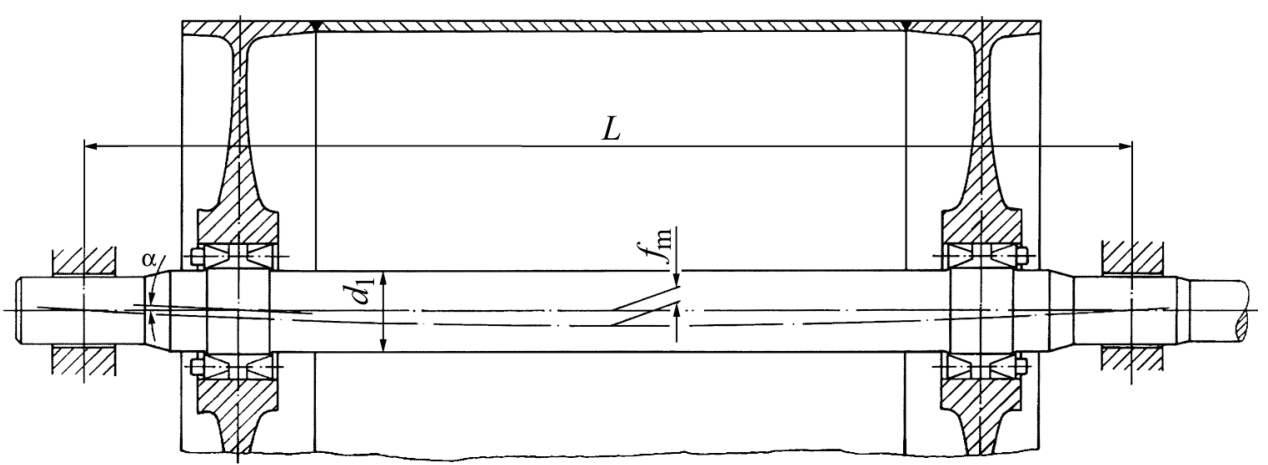

Figure 4 Driving drum

Under these circumstances, it is evident that only for pre-tensioning greater than $T_{\mathrm{p}}=320 \mathrm{kN}$ the belt conveyor with the above parameters can be started without any slip, while each slip of the belt results in additional loading of drive units, and particularly of dynamic character. Such worsened conditions have a direct impact on the lifetime of conveyor components of the belt conveyor including the drum lining. When reducing the belt pretensioning below $T_{\mathrm{p}}=270 \mathrm{kN}$ a permanent belt slippage occurs $\left(F_{\mathrm{rp}}\right.$ $<0$ ), which is unacceptable (see Fig. 5). 


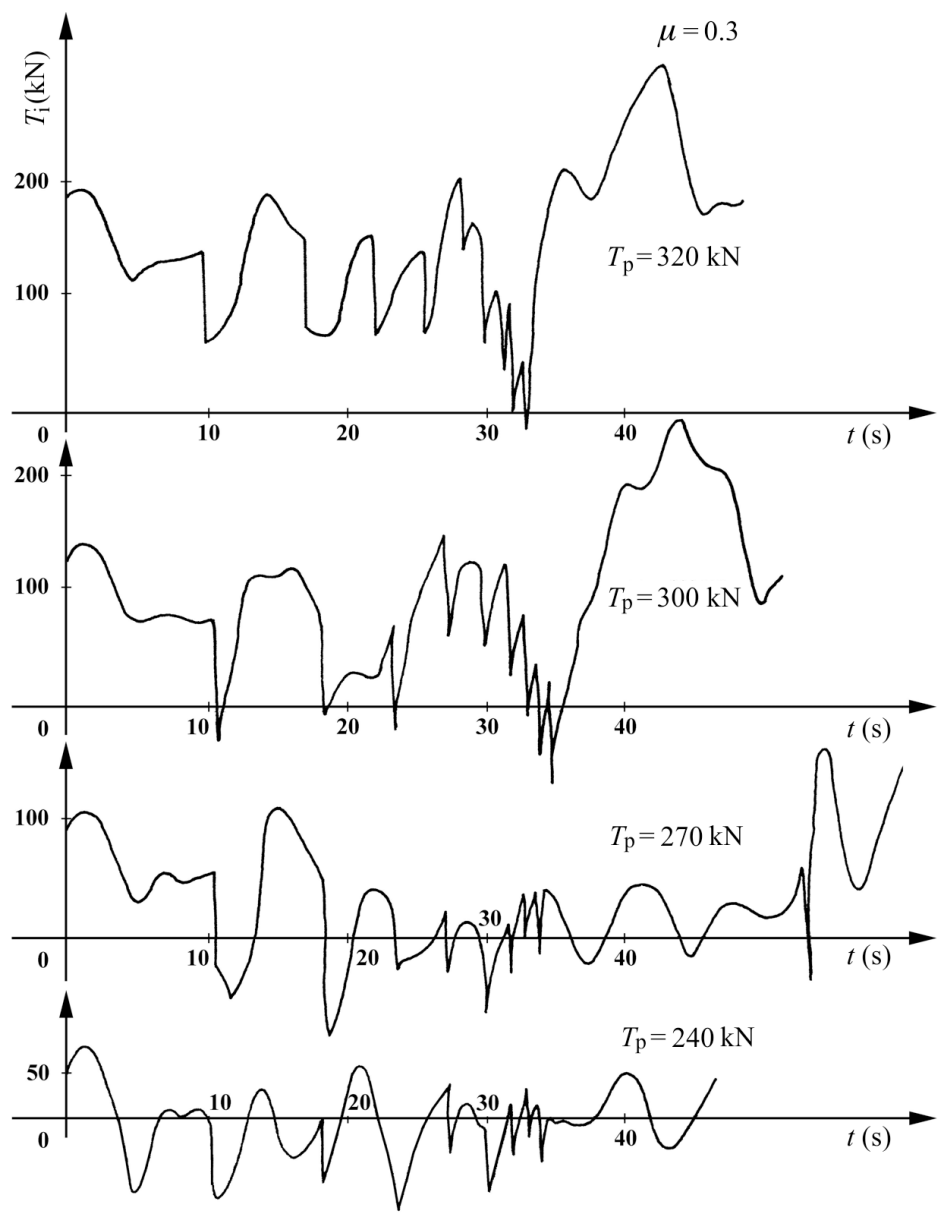

Figure 5 Curves of the reserve transmission capability of the drive drum - fully loaded

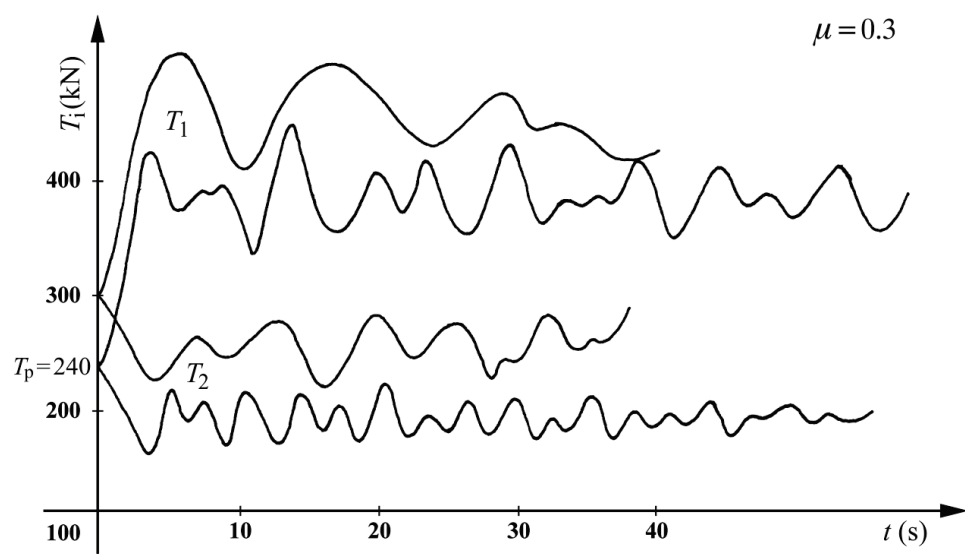

Figure 6 Curves of the approaching and receding forces of the drive drum $-25 \%$ of $\mathrm{BC}$ length before the drive drum is empty

Fig. 6 illustrates the curves of approaching force $\left(T_{1}\right)$ and receding force $\left(T_{2}\right)$ on the drive drum and Fig. 7 illustrates the behavior of the reserve transmission capability of the drive drum $F_{\mathrm{rp}}$ for the case when $25 \%$ of the conveyor length is not loaded in front of the drive drum.

The remainder ( $75 \%$ of the length) of the conveyor is fully loaded. It is obvious that such a loaded belt conveyor has its starting up characteristics slightly better (if not comparable) while keeping the other parameters, than the conveyor fully loaded.

Fig. 8 illustrates the behaviors of approaching force $\left(T_{1}\right)$ and receding force $\left(T_{2}\right)$ on the drive drum and Fig. 9 then behavior of the reserve transmission capability of the drive drum $F_{\text {rp }}$ for the case when $75 \%$ of the length of the conveyor in front of the drive drum is not loaded. The remainder ( $25 \%$ of the length) of the conveyor is fully loaded - at the return end conveyor.

It is obvious that such a loaded belt conveyor has much better starting up characteristics, while keeping the other parameters as of a fully loaded one, than the conveyor fully loaded. This is primarily due to loss of material and increased elasticity of the system.

Fig. 10 (for pre-tensioning the conveyor belt $T_{\mathrm{p}}=300$ $\mathrm{kN}$ ) and Fig. 11 (for pre-tensioning the belt $T_{\mathrm{p}}=280 \mathrm{kN}$ ) illustrates the behaviors of approaching force $\left(T_{1}\right)$, receding force $\left(T_{2}\right)$ and the curve of reserve transmission capacity $F_{\mathrm{rp}}$ on the drive drum for a step conveyor whose length is $L=100 \mathrm{~m}$. 

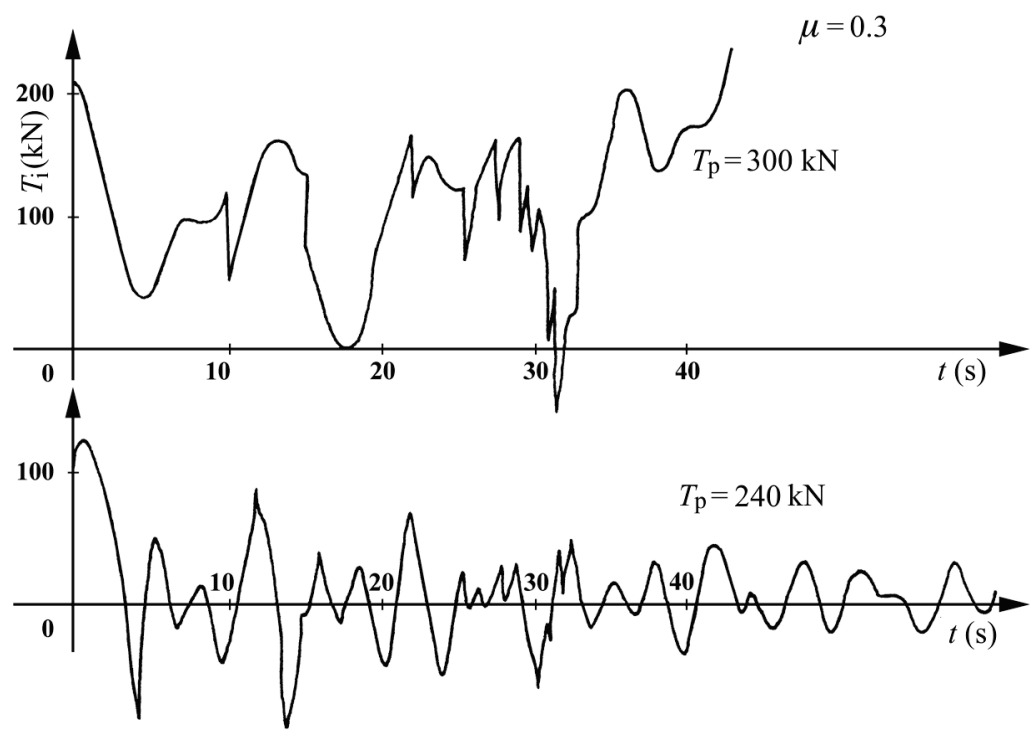

Figure 7 Curves of the reserve transmission capability - $25 \%$ of $\mathrm{BC}$ length before the drive drum is empty

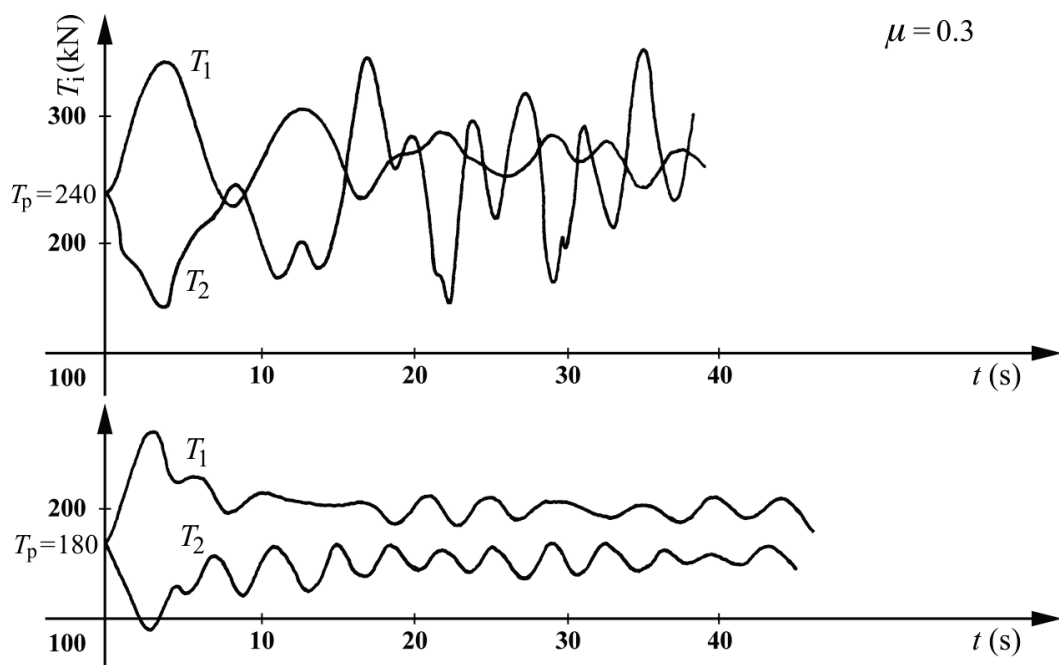

Figure 8 Curves of the approaching and receding forces of the drive drum $-75 \%$ of $\mathrm{BC}$ length before the drive drum is empty

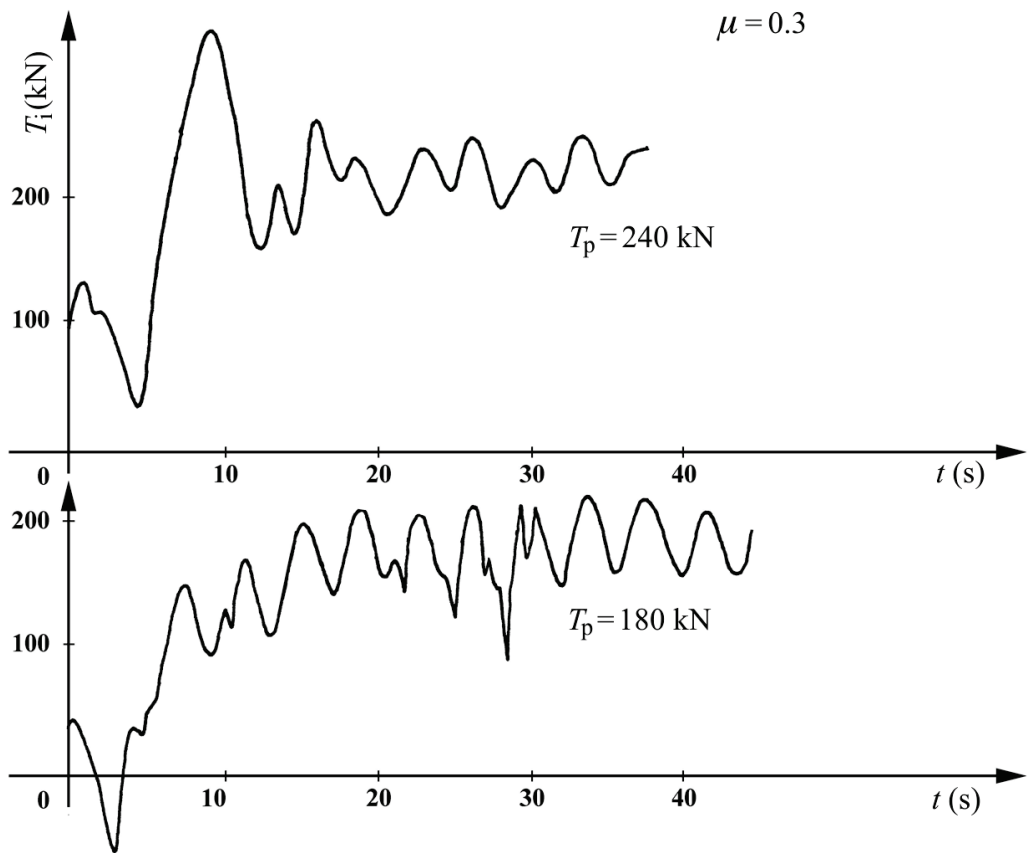

Figure 9 Curves of the reserve transmission capability of the drum $-75 \%$ of $\mathrm{BC}$ length before the drive drum is empty 


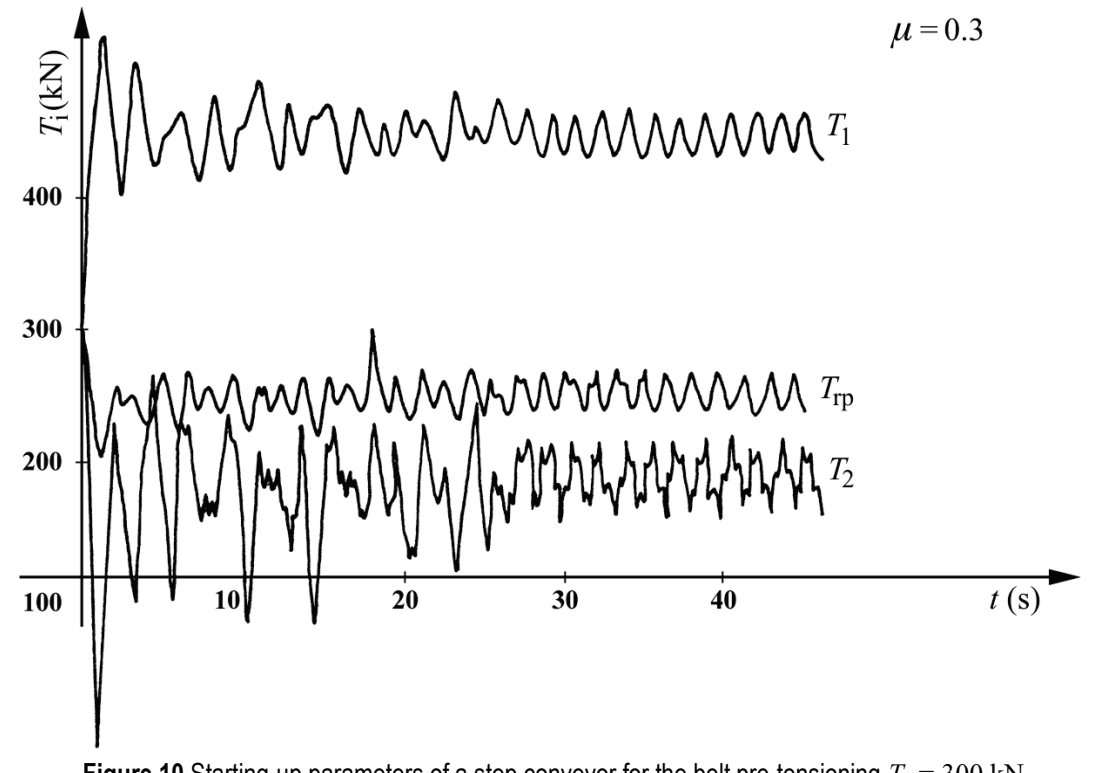

Figure 10 Starting-up parameters of a step conveyor for the belt pre-tensioning $T_{\mathrm{p}}=300 \mathrm{kN}$

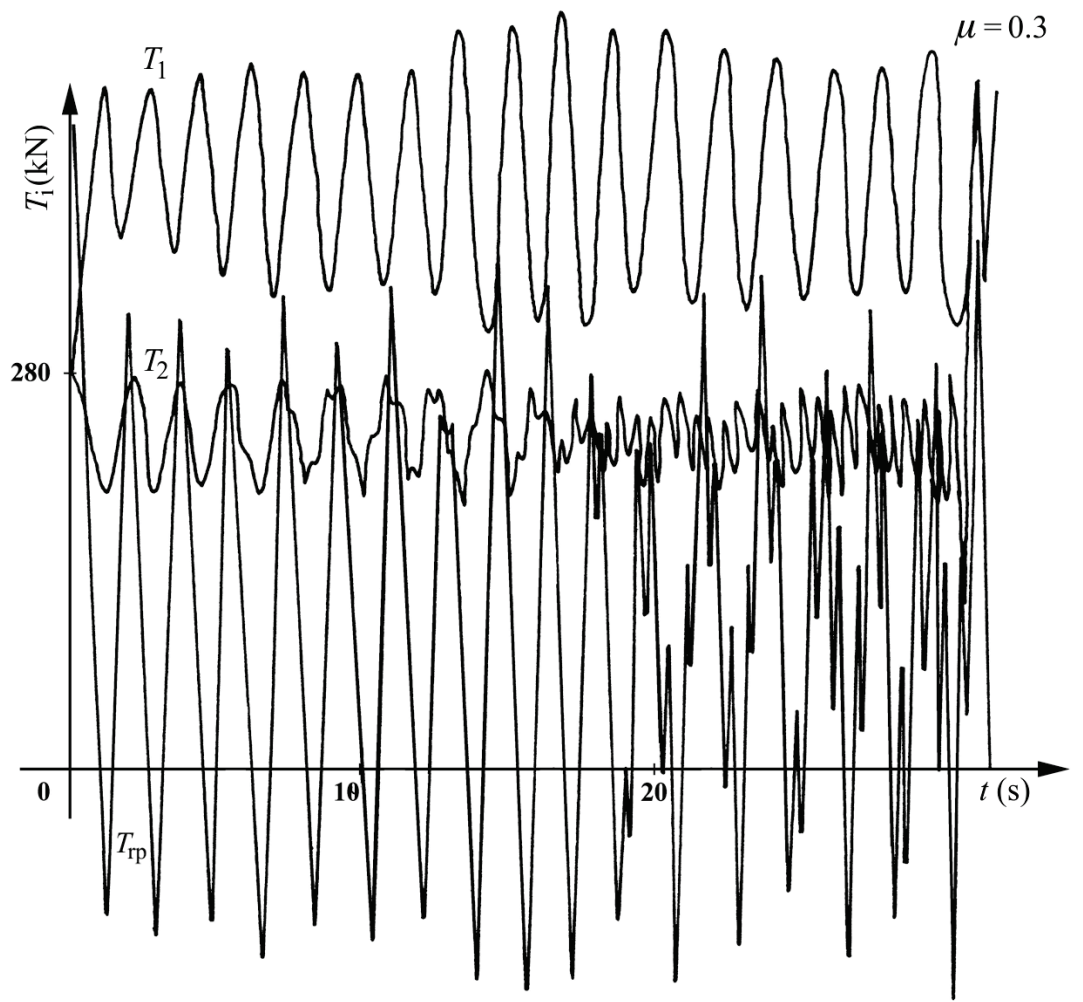

Figure 11 Starting-up parameters of a steep conveyor for the belt pre-tensioning $T_{\mathrm{p}}=280 \mathrm{kN}$

The elevation is $H=10 \mathrm{~m}$, while the conveyor is fully loaded along its entire length. Other parameters are the same as those of the above horizontally seated belt conveyor. It is obvious that a relatively small decrease on value of the conveyor belt pre-tensioning $T_{\mathrm{p}}$ results in a significant deterioration of the start-up characteristics. While for pre-tensioning equal to $300 \mathrm{kN}$ the conveyor starts up relatively at ease, with the reduction of the value by "only" $20 \mathrm{kN}$, i.e. to $280 \mathrm{kN}$, no start-up of the belt conveyor occurs whereas the slippage of the belt on the drive drum is permanent.

In Fig. 12 the start-up characteristics of the above type of conveyor with $75 \%$ belt filling towards the return end conveyor are indicated. The remaining part of the belt is empty. In case the belt pre-tensioning is $320 \mathrm{kN}$, the belt conveyor starts up without any major problems. Less slippage occurs predominantly at the beginning of its start-up. Reducing the pre-tensioning force leads to more frequent slips hampering the conveyor in start-up.

Fig. 13 shows again the curves of approaching force $\left(T_{1}\right)$, receding force $\left(T_{2}\right)$ and the curve of the reserve transmission capability $F_{\text {rp }}$ on the drive drum of the $800 \mathrm{~m}$ long conveyor, horizontally laid, i.e. with zero camber (fully loaded) for a reduced number of start-up steps from 9 to 6 . The negative effect of reducing the number of these steps is obvious. Only for a relatively considerable increase in the belt pre-tensioning to $350 \mathrm{kN}$ the start-up of the belt conveyor can occur, while several minor slips take place. 


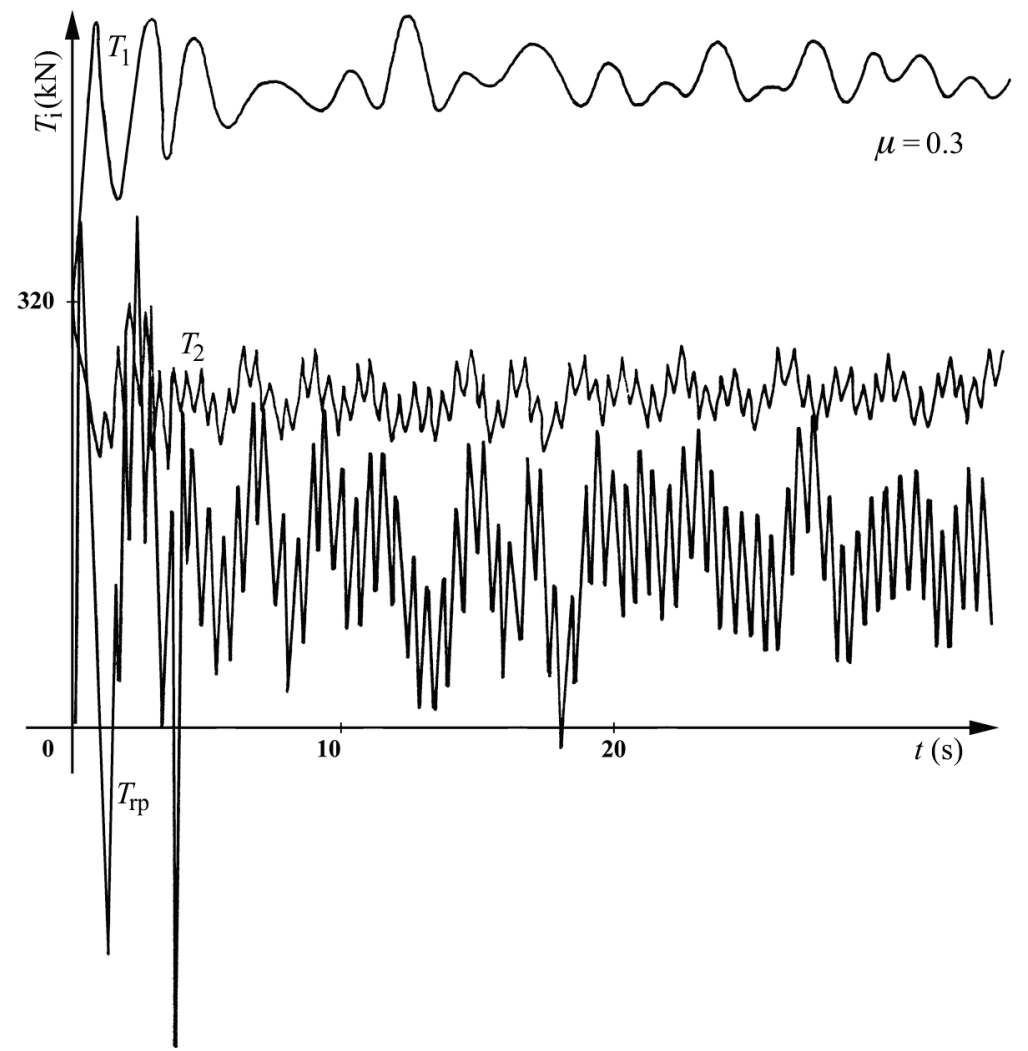

Figure 12 Starting-up parameters of a steep conveyor - $25 \%$ of $\mathrm{BC}$ length before the drive drum is empty

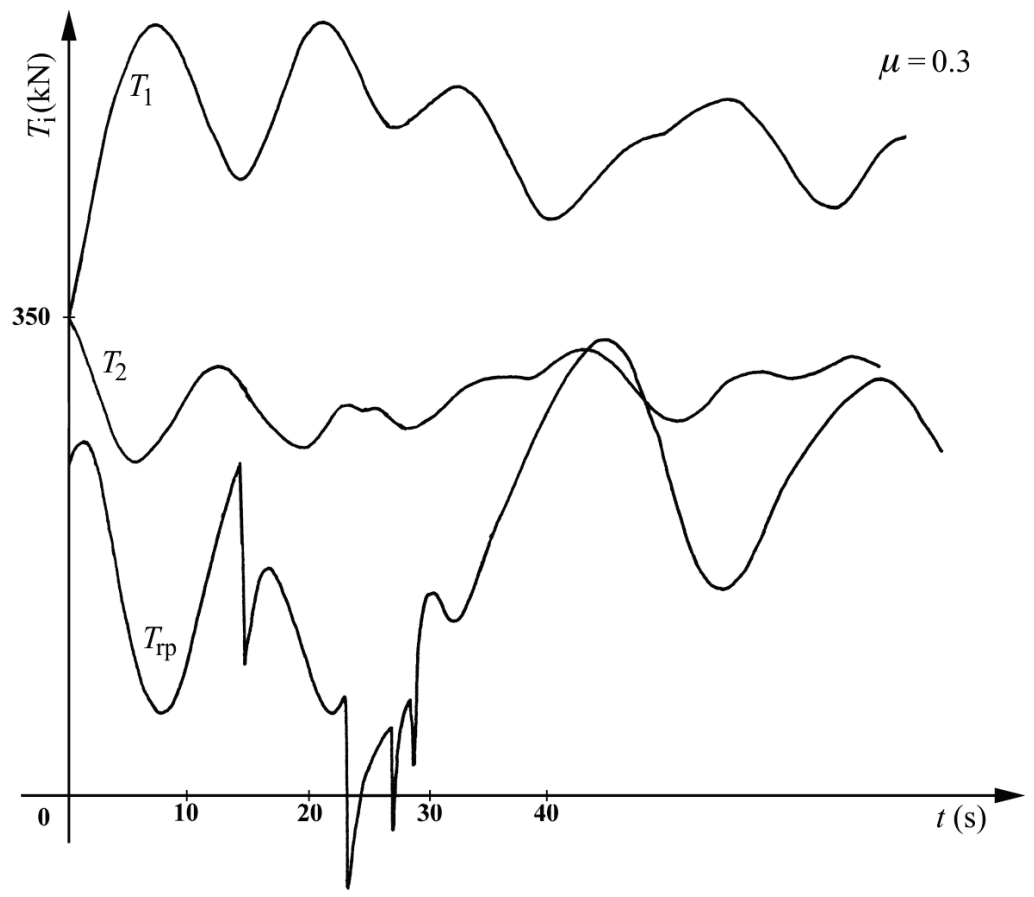

Figure 13 Start-up parameters of the horizontally seated conveyor for 6 start-up steps

The influence of input parameters on the emergence of slips:

- The fall in value of the coefficient of friction between the drum and the belt significantly reduces the transmission capability of the drive drum. To ensure the operating condition of the belt conveyor it is necessary to increase significantly the belt pretensioning - i.e. the tensioning force before start-up. The size of the coefficient of friction is in operation given by the surface design of the drive drum, immediate specific pressure in the contact area between the drum and the belt, surface condition of the drum and the running surface of the belt.

- The wrap angle, which is given by the design of the diving station and which remains almost unchanged when the conveyor is in operation, shows a similar effect.

- The size of the belt pre-tensioning - i.e. the tensioning force - is in fact the only parameter in operation of the belt conveyor which can be 
influenced. When its size is sufficient, the conveyor starts up smoothly and after the start-up completion a considerable reserve of the transmission capacity of the drive drum remains even if the pre-tensioning is reduced. Thus in steady operation the belt pretensioning can be reduced.

- In terms of the behavior of driving torque it is evident that in reducing the number of start-up steps larger dynamic shocks occur at each switch (the value of an immediate change of the drive torque is greater), which cause both belt slippage and also an increase in the stress of mechanical drive components. From this perspective, the steady increase in drive torque is ideal.

\section{CONCLUSION}

The solution of the dynamic model of the belt conveyor shows that the system behavior is very sensitive to the weight distribution along the route of BC. Starting up a long, fully loaded conveyor will be smoother than the conveyor partially loaded with material transported from the return end conveyor. The unloaded part of the belt before the drive drum will cause inequality and oscillation of the system, or short slips. Significant risks due to the possibility of slippage during the start-up occur for short inclined conveyors. Power of drives of those $\mathrm{BCs}$ is designed especially with regard to overcoming a height difference. Accelerated inertial masses and line resistances of the upper branch of the belt are relatively small. In the lower branch the gravitational component of belt weight in the direction of motion can be equivalent to the track resistances, so the movement of the belt lower branch does not need to be dampened. When the tuning (i.e. the ratio of stiffness of the belt to its own weight) is (not)suitable, the belt slippage can cause resonance vibrations of the $\mathrm{BC}$ lower branch. The above graphs (Fig. 10 and Fig. 11) show the oscillations of the lower branch initiated by the first slip on the drive drum. Each drop of the tensioning force $\mathrm{T}_{2}$ in the lower branch causes slippage; the system actuates itself by the change in coefficient of friction $\mu$ on the drive drum and gradually passes into the resonant vibrations of the lower branch. A decrease in belt pre-tensioning $T_{p}$ before start-up leads to accelerating the transition into resonant area.

The results of the belt conveyor start-up simulation can be summarized as follows:

- Belt slippage can under certain conditions cause vibration of the belt segment in the vicinity of driving drums, namely in both the upper and the lower branches of the belt, or in the segment between the drive drums. The development of vibrations is strongly damped and is not spread along the conveyor track.

- The biggest dynamic shocks do not arise during slipping itself, but at the moment of "catching" the belt at the periphery of the drive drum. Under certain circumstances, the belt "is not caught" at once, but still several times briefly slips. This causes a considerable dynamic shock both in the conveyor belt and in the bearing structure, drive, clutch, gearbox and especially in the drive drum, which can literally be torn apart - especially its shell. This method of "catching" a slip must be considered as a random phenomenon, since its formation and dynamic response is affected besides the parameters of the conveyor belt and drive also by the time when the "catching" occurs. This can cause both the damping of vibrations, as well as a significant dynamic response. The mentioned problems of belt conveyor drive units used on giant machines (i.e. bucket wheel excavators) can lead to a multiplication of the oscillation in the context of dynamic loading machine in question [3].

- During the 4.6 times simulation the tension was found in the upper belt branch compared to the tension value immediately after the slip was completed and a corresponding increase in the load of mechanical drive components and bearing structure. The gearbox load oscillated up to negative values.

- With regard to the randomness of the occurrence of dynamic shocks, their frequent incidences cannot be taken into account in operations of belt conveyors. However if occurred, they can cause the destruction of a belt joint, moving in the vicinity of the drive drum and can lead to a low-cycle fatigue of mechanical drive components and bearing system.

- The solution cannot be found in adjusting the conveyor dimensions, but especially in the design and use of appropriate control of its operation (including an active tensioning device reliable enough). The BC operation control, which responds just to the occurred slip of the belt on the drive drum, is unsatisfactory from this point of view.

- To size belt conveyors properly with regard to the occurrence of slips the calculations derived based on static understanding are not sufficient, but it is necessary to verify the calculation methodology on a dynamic model, or select or develop appropriate control systems.

\section{Acknowledgements}

The article has been done in connection with project Institute of clean technologies for mining and utilization of raw materials for energy use, reg. no. CZ.1.02/2.1.00/03.0082 supported by Research and Development for Innovations Operational Programme financed by Structural Founds of Europe Union and from the means of state budget of the Czech Republic and in connection with project FT-TA4/018 supported by the Czech Ministry of Industry and Trade.

\section{REFERENCES}

[1] Fries, J. (2003). Konstrukční řešení bubnů pásových dopravníků a jejich výpočet. Ostrava: VŠB - TU Ostrava, Fakulta strojní, $121 \mathrm{p}$.

[2] Fries, J. (2009). Pásové dopravníky, bubny a jejich výpočet. Ostrava: VŠB - TU Ostrava, Fakulta strojní, 189 p.

[3] Gottvald, J. (2010). The calculation and measurement of the natural frequencies of the bucket wheel excavator Schrs 1320/4x30. Transport, 25(3), 269-277. https://doi.org/10.3846/transport.2010.33

[4] Toušek, E. (1985). Prokluz pásu na poháněcím bubnu pásového dopravníku - kandidátská práce. Praha. ČVUT, $145 \mathrm{p}$. 


\section{Contact information:}

Jiří FRIES, Assoc. Prof., Ing., PhD

VŠB - Technical University of Ostrava

Faculty of Mining and Geology

Institute of clean technologies for mining and utilization of raw materials for

energy use

17. listopadu $15 / 2172$

70833 Ostrava - Poruba

Czech Republic

+420 597324207, jiri.fries@vsb.cz

Tomáš HAPLA, Ing.

VŠB - Technical University of Ostrava

Faculty of Mechanical Engineering

17. listopadu $15 / 2172$

70833 Ostrava - Poruba

Czech Republic

+420 597324213, tomas.hapla@vsb.cz 